\title{
Retrospective Analysis of the Effect of Alcohol Abuse and Restraining Device on Maxillofacial Injury- A Study of 225 Cases
}

\author{
Maina Bekal ${ }^{1}$, Brijesh K. ${ }^{2}$, Suresha K. R. ${ }^{3}$ \\ ${ }^{1}$ Department of Dentistry, Akash Institute of Medical Sciences and Research Centre, Bangalore, Karnataka, India. \\ ${ }^{2}$ Department of Anaesthesiology and Critical Care, Akash Institute of Medical Sciences and Research Centre, \\ Bangalore, Karnataka, India. ${ }^{3}$ Department of Pharmacology, Akash Institute of Medical Sciences and Research Centre, \\ Bangalore, Karnataka, India.
}

\section{ABSTRACT}

\section{BACKGROUND}

Trauma is the most common cause of maxillofacial injury. Maxillofacial injuries can cause long-term functional, aesthetic, and psychological complication. Road traffic accidents (RTA) are the major causes in developing countries like India. Restraint devices significantly reduce the risk and severity of injury, and the number of deaths resulting from crashes. RTA is often related to the use of alcohol and has a strong association with facial injuries. The present study evaluated the demographic pattern, aetiology, management of maxillofacial injuries, its association of alcohol abuse and the effect of restraint/protective devices influencing their distribution.

\section{METHODS}

A four-year retrospective study was done between January 2014 to December 2017 on patients with maxillofacial injuries attending dental OPD and emergency department. A total of 225 patients with maxillofacial injury/trauma were analysed. Age ranged between 5-75 years. Patient with head injury, polytrauma and pregnant females were excluded from the study. Patients were evaluated by age, gender, mode of injury, aetiology, history of alcohol intake, maxillofacial injury sites, use of protective device at the time of injury and treatment rendered. Data was expressed in percentages.

\section{RESULTS}

A total of 225 patients accounting for 288 maxillofacial fractures were included and analysed. The male:female ratio was 3:1. Commonly affected age group was 21-30 year (49.3\%). Road traffic accidents accounted for $49.01 \%$. Two wheelers were the most commonly involved vehicle. Mandible was the most commonly fractured site. Patients under the influence of alcohol contributed to more number of maxillofacial injuries. Also, non-use of restraining device increased the incidence of facial injury.

\section{CONCLUSIONS}

RTA with two wheelers is the most common aetiology of maxillofacial injuries, involving young adult (21-40 years) male patients. Mandible is most commonly fractured. Not using safety measures (helmets and seat belts) and also influence of alcohol are the major factors responsible for the injuries.

\section{KEY WORDS}

Maxillofacial Injury, Alcohol Abuse, Helmet, Road Traffic Accidents
Corresponding Author: Dr. Brijesh K.,

Department of Anaesthesiology \& Critical Care, Akash Institute of Medical Sciences and Research Centre, Devanahalli-562110, Bangalore Rural, Karnataka, India. E-mail: brijeshkumar291@yahoo.co.in

DOI: $10.14260 / \mathrm{jemds} / 2019 / 762$

Financial or Other Competing Interests: None.

How to Cite This Article:

Bekal $M$, Brijesh $K$, Suresha KR. Retrospective analysis of the effect of alcohol abuse and restraining device on maxillofacial injury- a study of 225 cases. J. Evolution Med. Dent. Sci. 2019;8(47):35263530, DOI: 10.14260/jemds/2019/762

Submission 10-07-2019,

Peer Review 04-11-2019,

Acceptance 11-11-2019,

Published 25-11-2019. 


\section{BACKGROUND}

Maxillofacial injuries range from isolated injuries involving only one or two components of the facial skeleton to complex facial injuries involving the entire facial skeleton. ${ }^{1}$ The magnitude and aetiology of oral and maxillofacial injuries varies from one geographic region to another or even within the same region depending on the prevailing socioeconomic,

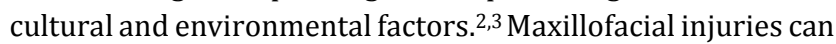
cause long-term functional, aesthetic, and psychological complication. ${ }^{4}$ Also these injuries may lead to substantial economic consequence on the patients. The main causes of maxillofacial injuries are road traffic accidents (RTAs), assaults, falls, sports-related injuries and wars. Road traffic accidents (RTA) are the major cause of maxillofacial injuries in the developing countries like India. ${ }^{5}$ However usage of restraint devices significantly reduces the risk and severity of injury, and also reduces the number of deaths resulting from crashes. ${ }^{6}$ Trauma is often related to the use of alcohol and its abuse has reached massive proportions, ${ }^{7}$ no matter if the country is developed or not, it is being considered as public health problem. Furthermore, alcohol has a strong association with facial injuries due to interpersonal violence and motor vehicle accidents. ${ }^{8}$ Analysis of the causes and types of facial bone fractures provides some important guidelines for the prevention and treatment of fractures in the future. Therefore, there have been multiple studies on this issue. ${ }^{9}$ With this background the present study was conducted in our centre which is closely located near national highway road where many RTA cases are treated. This study evaluated the pattern, aetiology, management of maxillofacial injuries, association of alcohol abuse and assessed the various factors like restraint/protective devices influencing their distribution. Such epidemiological data helps in planning of the future public health programs directed at prevention of accidents.

\section{METHODS}

The study was conducted at the department of dentistry, Akash institute of medical sciences and research centre, Bangalore. The data was obtained from the case record sheets of 225 patients who reported to the dental OPD and casualty during the period from January 2014 to December 2017. Study design: retrospective study was conducted after institution ethical committee approval. A proforma was prepared for the collection of data from case records such as patients age, sex, aetiology, history of alcohol intake, type of injury which included soft tissue injury and fracture, radiographs (OPG and CT scans), use of protective device at the time of injury and treatment rendered (Closed reduction, open reduction and internal fixation for maxillofacial fractures, soft tissue repair for lacerations, contusions and abrasions under local or general anaesthesia)

\section{Inclusion Criteria}

The patients of either gender between aged between 5-75 years, with isolated maxillofacial injuries were included in the study.

\section{Exclusion Criteria}

Unconscious patients, head injury patients, poly trauma patients and pregnant females were excluded from the study.

The aetiology of injury was categorized into five main categories: Road traffic accident (RTA) involving automobiles, motorcycle which included drivers, pillion riders, passengers, and pedestrians, (b) Self fall, (c) Assaults or interpersonal violence, (d) Work related injury, (e) Sports injuries.

Fractures were assessed according to location that is exclusively lower third, middle third and combination of both middle third and lower third of the face. Sites of mandibular fractures were classified as symphysis, parasymphysis, body, angle, ramus, condyle, coronoid and dentoalveolar. Sites of mid-facial fractures were classified as maxilla, zygoma, nasoorbito-ethmoid, isolated zygomatic arch, orbital floor, nasal. The maxillary fractures were classified according to Lefort classification. ${ }^{10}$

Vehicles were divided into two categories, category A: twowheel vehicle (e.g. motorcycle) and category B: four-wheel vehicle (light motor vehicle and heavy motor vehicle).

\section{Statistical Analysis}

The data was entered into MS Office Excel 2016 and subjected to statistical analysis using Instat GraphPad. The data obtained were statistically analysed and following content analysis the data were interpreted using percentage.

\section{RESULTS}

During the study period, a total of 225 patients were included and a total of 288 maxillo-facial fractures were analysed.

\section{Demographic Pattern}

The male: female ratio was 3:1. Males outnumbered females. Gender wise Distribution of the Maxillofacial injuries is shown in Chart 1A. The patient age ranged from 5 to 75 years; most affected age group was from 21-30 year (49.3\%) followed by patients in the age group between 31-40 year (24\%). Age wise distribution of the injury is shown in Chart 1B.

\section{Mechanism/Aetiology of Maxillofacial Injury}

The most frequent aetiology of maxillofacial injury was road traffic accident [RTA] accounting for $65.3 \%$ of patients followed by self-fall (16\%). The mechanism/aetiology of maxillofacial injury is shown in Chart 2.

Type of Vehicle Used/Association of Alcohol Consumption $74 \%$ of male patients (108/147) were under the influence of alcohol at the time of injury. Among the RTA motorized twowheeler accidents accounted in 129 patients (87.7\%).The accidents included skids and falls, collision with other vehicles and pedestrians. The type of vehicle and alcohol intoxication in Road Traffic Accident is shown in Chart 3.

\section{Analysis of Type of Fracture/Injury and Anatomical Site}

The anatomical site of maxillofacial fracture/injury is shown in Chart 4A. Analysis shows that mandibular fractures were common and accounted for $32.26 \%$ of fractures (93/288). Maxillary fracture was seen in 15 patients (5.2\%), and nasal 
bone fractures in 12 patients (4.16\%), zygomatico maxillary complex fractures accounted for 26.04\%(75/288), 20.8\% $(60 / 288)$ caused isolated soft tissue injury of the face, $11.4 \%$ were dento-alveolar fractures $(33 / 288)$. Chart $4 \mathrm{~B}$ shows that among the mandibular fractures, symphysis and parasymphysis fracture were the most common fracture sites in 51 cases $(17.7 \%)$.

\section{Analysis of Treatment and Type of Anaesthesia}

$38.6 \%$ of patients $(87 / 225)$ were treated by closed reduction and arch bar fixation under local anaesthesia, $34.7 \%$ of patients (78/225) were treated with open reduction and internal fixation (ORIF) under general anaesthesia, Isolated Soft tissue injuries requiring tissue repair and dressing under local anaesthesia were performed in $26.7 \%(60 / 225)$ patients which were mostly located extraorally and included contusion, lacerations and abrasions. Chart 5 shows the treatment rendered (closed reduction/ open reduction and internal fixation) and type of anaesthesia given (local anaesthesia/ general anaesthesia).

\section{Analysis of Restraint Device Used at the Time of Injury}

The Use/non-use of restraint devices and severity of maxillofacial injuries are shown in Chart 6. There were 129 patients $(87.8 \%)$ in category $\mathrm{A}$ vehicles and 18 patients $(12.2 \%)$ in category B vehicles. Among 129 patients in category A, 120 patients $(93.02 \%)$ were not wearing the helmet while 9 patients (6.97\%) were wearing the helmet during the RTA. In category B, 12 patients (66.7\%) were wearing the seat belt whereas 6 patients $(33.3 \%)$ were not wearing the seat belt.

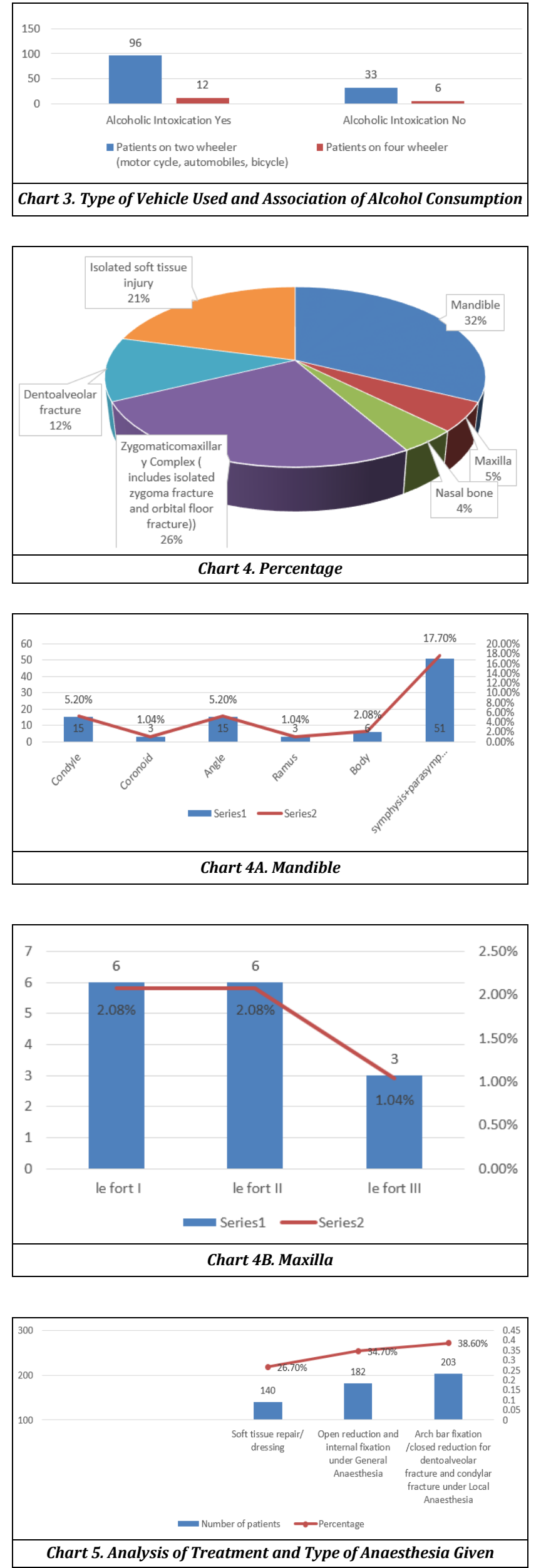


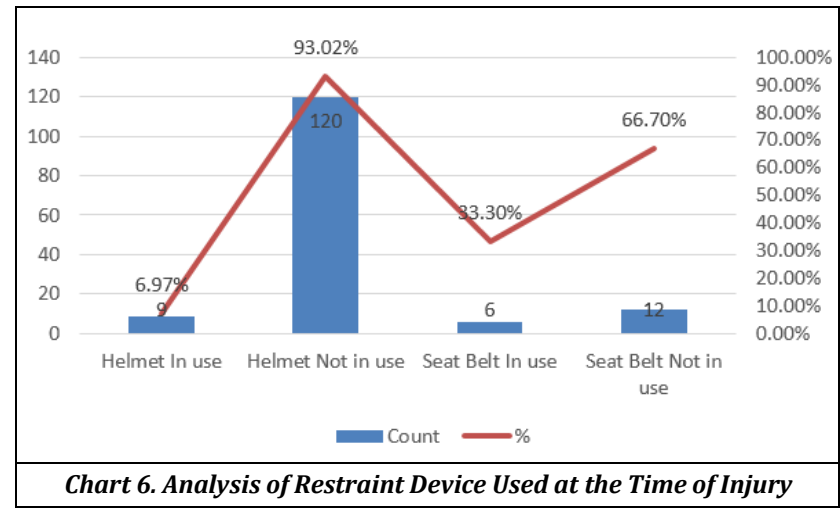

\section{DISCUSSION}

Trauma is one of the major causes of death among people under 40 years of age ${ }^{11}$. The cost of injury is higher than those of any other health problems and roughly equals to the costs associated with heart diseases and cancers. ${ }^{12}$ The number of maxillofacial injuries is continuously associated with the use of alcohol and illicit drugs during driving leads to RTA. This account for $90 \%$ of the fatalities due to RTA occurs in developing countries. ${ }^{13}$ The average ratio of male to female was $3: 1$, this can be explained by the fact that in developing countries men are active member of the family and do remain outdoor for a larger period of time and are more vulnerable to alcohol consumption, accidents, assaults, violation of traffic than women. This finding is in accordance with findings reported by Shankar et al ${ }^{14}$ and Gupta $R$ et al. ${ }^{15}$

In the current study the common age group affected was $21-30$ years $(49.3 \%)$ followed by $31-40$ years (24\%). This may be due to the fact that this age group is more active, suffer more traumas due to more outdoor activities, indulge in high speed and careless rash driving tendencies. This finding is consistent with study by Kapoor et al and Chandrashekahar et al. ${ }^{16,17}$ In our study the RTA was the most common cause of maxillofacial trauma (65.3\%).And is consistent with Gandhi et al ${ }^{18}$ and Subhashraj et al. ${ }^{19}$ In rural India motorized twowheeler vehicles are registered in more number $(70 \%)$ compared to light/heavy motor vehicles. Since our institution is a referral center located in rural area with close proximity to National highway aid in predominantly treating low income group and their main mode of transportation are motorized two wheelers (bike, scooter) and bicycle. Among the patients with maxillofacial injuries, 129 patients used motorized twowheeler (Category A) and 18 patients were on four-wheeler (Category B); among them 53.3\% (120 patients) were male and $12 \%$ (27 patients) were female.

In our study the commonest bone fractured was mandible 93 patients (32.26\%), followed by zygomatico-maxillary fracture 75 patients $26.04 \%$ ), dento-alveolar fracture 33 patients(11.4\%), maxillary fracture 15 patients $(8.32 \%)$ and nasal bone fracture 12 patients $(4.16 \%)$. The isolated soft tissue injury was seen in 60 patients $(20.8 \%)$. This findings are similar to previous studies reported in the literatures Shankar et al and Kapoor et al.14,16 Mandible is most vulnerable because of its position and predominance on face, osteology of mandible, the influence on the presence of developing or completed dentition all play a role in weakness of the lower jaw ${ }^{20}$. The restraint devices (Semi-helmets) are not protective in lower part of face leads to easy mandible injuries. In our study 120 patients did not use helmets and 9 patients used helmets while driving. Also 12 patients wore seat belt and 6 patients did not wear seat belt. These results are consistent with Pandey S et al. ${ }^{27}$ Many authors have consistently linked alcohol abuse and motor bike accidents 20,21. Our study revealed 114 patients were under the influence of alcohol at the time of injury. These results are consistent with Singh et $\mathrm{al}^{22}$ Prabhu et al23. Reduction of drunk drivers and adaptation of safety devices reduces maxillofacial trauma severity. ${ }^{24}$

There are many treatment regimens in maxillofacial fracture, but the treatments chosen may differ depending on cost of treatment, affordability, feasibility, patient's willingness to avail the treatments and skill and experience and expertise of operating surgeons. Even though open reduction and internal fixation is gold standard treatment, most of the patients (38.6\%) were treated in our institution with closed reduction with arch bar fixation, despite many challenges like malocclusion, asymmetry, nutrition, oral hygiene and pain, our study results are consistent with Marker et al, Worsaae et al and Pandey S et al.25,26,27 and (34.7\%) with open reduction and internal fixation (ORIF) with antimicrobial agents. Soft tissue repair/dressing was done in $(26.7 \%)$ patients.

Post operatively the malocclusion and infection were the most common complications in mandible fracture. The incidences of post-operative complications vary from 8-11\%. Complication includes infection, malocclusion, mal-union, scar formation and ophthalmic complication. In our study, the complication i.e. post-operative infection was seen only in 9 patients $(0.6 \%)$, this may be because of aseptic and infection control measures, pre-operative prophylaxis and skills of the surgeons.

\section{CONCLUSIONS}

RTA with two wheelers is the most common aetiology of maxillofacial injuries involving young adult (21-40 years) male patients. Mandible is most commonly fractured. Not using safety measures (helmets and seat belts) and also influence of alcohol are the major factors responsible for the injuries. Majority of the injuries are treated with closed reduction under local anaesthesia and ORIF were performed in indicated fracture patients. Preventive measures such as wearing helmets, wearing seat belts, reinforcement of road safety and traffic rules by traffic police, adherence to the traffic rules and regulations by the local people, provision of pedestrian path, segregation of heavy and light motor vehicles, denying insurance coverage to alcohol abusers, timely maintenance of faulty roads, endorsement of psychosocial aftercare programs to reduce the risk of re-injury and promotion of patient compliance should be introduced.

\section{REFERENCES}

[1] Fonseca RJ, Walker RV. Oral and maxilofacial trauma. Vol. 1. $3^{\text {rd }}$ edn. Philadelphia: W.B. Saunders Company, 1997. 
[2] Maslika MC, Lima Jr SM, Gil JN. Analysis of 185 maxillofacial fractures in the state of Santa Catarina, Brazil. Braz Oral Res 2009;23(3):268-74.

[3] Gandhi S, Ranganathan LK, Solanki M, et al. Pattern of maxillofacial fractures at a tertiary hospital in northern India: a 4 year retrospective study of 718 patients. Dent Traumatology 2011;27(4):257-62.

[4] Hull AM, Lowe $T$, Devlin $M$, et al. Psychological consequences of maxillofacial trauma: a preliminary study. Br J Oral Maxillofac Surg 2003;41(5):317-22.

[5] Karne M, Mishra S, Ashish T, et al. Study of pattern of injuries by road traffic accident on National Highway-24. International Journal of Contemporary Surgery 2017;5:37-41.

[6] Stacey DH, Doyle JF, Gutowski KA. Safety device use affects the incidence patterns of facial trauma in motor vehicle collisions: an analysis of the National Trauma Database from 2000 to 2004. Plast Reconstr Surg 2008;121(6):2057-64.

[7] Rehm J, Gmel G, Sempos CT, et al. Alcohol-related morbidity and mortality. Alcohol Res Health 2003;27(1):39-51.

[8] Carvalho TB, Cancian LR, Marques CG, et al. Six years of facial trauma care: an epidemiological analysis of 355 cases. Braz J Otorhinolaryngol 2010;76(5):565-74.

[9] Kim HG, Son YH, Chung IK. Facial bone fracture patients visiting Pusan National University hospital in Busan and Yangsan: trends and risks. Maxillofac Plast Reconstr Surg 2014;36(4):140-5.

[10] Holt GR. Resident manual of trauma to the face, head and neck. 1st edn. American Academy of Otolaryngology Head and Neck Surgery Foundation. 2012.

[11] Gassner R, Tuli T, Hächl 0, et al. Cranio-maxillofacial trauma: a 10 year review of 9,543 cases with 21,067 injuries. J Craniomaxillofac Surg 2003;31(1):51-61.

[12] National Center for Injury Prevention and Control. Injury Fact Book 2001-2002. Centers for Disease Control and Prevention, Atlanta, GA: 2001:6.

[13] Adeyemo WL, Ladeinde AL, Ogunlewe MO, et al. Trends and characteristics of oral and maxillofacial injuries in Nigeria: a review of the literature. Head Face Med 2005;1:7.

[14] Shankar AN, Shankar VN, Hegde N, et al. The pattern of the maxillofacial fractures-a multicenter retrospective study. J Craniomaxillofac Surg 2012;40(8):675-9.

[15] Gupta R, Suryanarayan S, Sharma A, et al. Traumatic mandibular fractures: pendulum towards closed reduction. The World Articles in Ear, Nose and Throat 2010;3:1-3

[16] Kapoor P, Kalra N. A retrospective analysis of maxillofacial injuries in patients reporting at a tertiary care hospital in East Delhi. Int J Crit Iln Inj Sci 2012;2(1):610.

[17] Chandrashekhar BR, Reddy CV. A five year retrospective statistical analysis of maxillofacial injuries in patients admitted and treated at two hospitals of Mysore city. Indian J Dent Res 2008;19(4):304-8.

[18] Gandhi S, Ranganathan LK, Solanki M, et al. Pattern of maxillofacial fractures at a tertiary hospital in northern India: a 4 year retrospective study of 718 patients. Dent Traumatol 2011;27(4):257-62.

[19] Subhashraj K, Nandakumar N, Ravindran C. Review of maxillofacial injuries in Chennai, India: a study of 2748 cases. Br J Oral Maxillofac Surg 2007;45(8):637-9.

[20] Kamulegeya A, Lakor F, Kabenge K. Oral maxillofacial fractures seen at a Ugandan tertiary hospital: a six month prospective study. Clinics (Sao Paulo) 2009;64(9):843-8.

[21] Lee KH, Snape L. Role of alcohol in maxillofacial fractures. N Z Med J 2008;121(1271):15-23.

[22] Singh R, Singh HK, Gupta SC, et al. Pattern, severity and circumstances of injuries sustained in road traffic accidents: a tertiary care hospital-based study. Indian J Community Med 2014;39(1):30-4.

[23] Prabhu P, Srinivas R, Vishwanathan K, et al. Factors influencing alcohol and tobacco addiction among patients attending a de-addiction Centre, South India. J Int Soc Prev Community Dent 2014;4(2):103-7.

[24] Laverick S, Patel N, Jones DC. Maxillofacial trauma and the role of alcohol. Br J Oral Maxillofac Surg 2008;46(7):5426.

[25] Marker P, Nielsen A, Bastian HL. Fractures of the mandibular condyle. Part 2: results of treatment of 348 patients. Br J Oral Maxillofac Surg 2000;38(5):422-6.

[26] Worsaae N, Thorn JJ. Surgical versus nonsurgical treatment of unilateral dislocated low subcondylar fractures: a clinical study of 52 cases. J Oral Maxillofac Surg 1994;52(4):353-60.

[27] Pandey S, Roychoudhury A, Bhutia O, et al. Study of the pattern of maxillofacial fractures seen at a tertiary care hospital in North India. J Maxillofac Oral Surg 2015;14(1):32-9. 